\title{
Malignant Spinal Cord Neoplasm
}

National Cancer Institute

\section{Source}

National Cancer Institute. Malignant Spinal Cord Neoplasm. NCI Thesaurus. Code C3572.

A primary or metastatic malignant neoplasm affecting the spinal cord. Representative examples include lymphoma, melanoma, and sarcoma. 